\title{
Mitochondrial dysfunction in Trypanosoma cruzi: the role of Serratia marcescens prodigiosin in the alternative treatment of Chagas disease
}

\author{
Carlos Genes ${ }^{1}$, Eduard Baquero², Fernando Echeverri², Juan D Maya ${ }^{3}$ and Omar Triana ${ }^{1 *}$
}

\begin{abstract}
Background: Chagas disease is a health threat for many people, mostly those living in Latin America. One of the most important problems in treatment is the limitation of existing drugs. Prodigiosin, produced by Serratia marcescens (Rhodnius prolixus endosymbiont), belongs to the red-pigmented bacterial prodiginine family, which displays numerous biological activities, including antibacterial, antifungal, antiprotozoal, antimalarial, immunosuppressive, and anticancer properties. Here we describe its effects on Trypanosoma cruzi mitochondria belonging to TCI and TC II.

Results: Parasites exposed to prodigiosin altered the mitochondrial function and oxidative phosphorylation could not have a normal course, probably by inhibition of complex III. Prodigiosin did not produce cytotoxic effects in lymphocytes and Vero cells and has better effects than benznidazole. Our data suggest that the action of prodigiosin on the parasites is mediated by mitochondrial structural and functional disruptions that could lead the parasites to an apoptotic-like cell death process.

Conclusions: Here, we propose a potentially useful trypanocidal agent derived from knowledge of an important aspect of the natural life cycle of the parasite: the vector-parasite interaction. Our results indicate that prodigiosin could be a good candidate for the treatment of Chagas disease.
\end{abstract}

\section{Background}

Chagas disease continues to represent a health threat for an estimated 28 million people, most of them living in Latin America. One of the most important problems in the outcome of Chagas disease is the limitation of existing drugs for treatment [1]. For more than 40 years, only two drugs, nifurtimox and benznidazole, have been available to treat Chagas disease. Both have limited efficacy (about $80 \%$ efficacy in the acute phase and lower in the chronic phase), as well as frequent and significant side effects [2]. Other potentially beneficial drugs, such as allopurinol or itraconazole, do not have a high enough degree of clinical efficacy, as compared with nifurtimox or benznidazole; Posaconazole is a promising drug, but expensive [2]. Furthermore, hundreds of natural and synthetic compounds have been tested against

\footnotetext{
* Correspondence: omar.triana@siu.udea.edu.co

'Grupo Biología y Control de Enfermedades Infecciosas BCEI - SIU, Instituto de Biología, Universidad de Antioquia, Medellín, Colombia

Full list of author information is available at the end of the article
}

the protozoan parasite Trypanosoma cruzi, the causative agent of Chagas disease. However, very few are devoid of cytotoxic activity or have proved more efficacious than nifurtimox and benznidazole, especially against the intracellular amastigotes [3]. Therefore, disease control is mainly based on the elimination of insect vectors. Most species of the Triatominae (Hemiptera-Reduviidae) subfamily are potential vectors of $T$. cruzi. It has been reported that in the first few days after a blood meal, the number of bacteria in the anterior midgut (stomach) of Rhodnius prolixus increases dramatically. In addition, many of the bloodstream trypomastigotes are lysed in the vector's stomach. This probably occurs as part of a complex ecological interaction in the vector, where bacteria play a central role [4]. A wide variety of bacteria including species from the Actinobacteria, Firmicutes, and Proteobacteria have been detected in the triatomine midgut tract [5,6]. It has been reported that Serratia marcescens biotype A1a has trypanolytic activity in the gut of the vector Rhodnius prolixus, especially on the $\mathrm{Y}$
C Biomed Central

(c) 2011 Genes et al; licensee BioMed Central Ltd. This is an Open Access article distributed under the terms of the Creative Commons Attribution License (http://creativecommons.org/licenses/by/2.0), which permits unrestricted use, distribution, and reproduction in any medium, provided the original work is properly cited. 
strain [7]. The prodigiosin produced by this bacterium could be responsible for the trypanocidal activity observed in the vector.

Prodigiosins, which belong to the red-pigmented bacterial prodiginine family, are tripyrrolic compounds that display numerous biological activities, including antibacterial, antifungal, antiprotozoal, antimalarial, immunosuppressive, and anticancer properties [8,9]. This broad spectrum of activities might be related to their capacity to alter key proteins involved in cell cycle or intracellular signal transduction or to induce apoptosis [10]. Certainly, there is abundant evidence indicating that bacterial prodiginines and synthetic derivatives are effective proapoptotic agents with multiple cellular targets, and they are active against numerous cancer cell lines, including multidrug-resistant cells [9]. Very important is the demonstration of little or no toxicity toward normal cell lines. For this reason a synthetic derivative of prodiginines, GX15-070 (Obatoclax), developed through structure-activity relationship studies of the pyrrolic ring A of GX15, is in multiple Phase I and II clinical trials in both single- and dual-agent studies to treat different types of cancer $[8,11]$.

Therefore, prodiginines have real therapeutic potential and although their mode of action is not yet clear and can vary depending on cell type, it has been reported that their effects can strongly compromise the mitochondrial metabolism. The mitochondrial disturbances can be evidenced by alterations in cellular respiration, energy balance, or even structural modifications on the organelle as proposed recently [12-14]. All these alterations suggest that the prodigiosin effects could result in an apoptotic process on cells [13-15].

Here we provide data on the selective trypanocidal activity of prodigiosin, evidenced by low cytotoxicity against a normal cell line and human lymphocytes. Additionally, we compare the effects of several mitochondrial electron transport chain (ETC) inhibitors, to propose the mitochondria as a possible target for prodigiosin effects on $T$. cruzi.

\section{Results}

Trypanocidal activity of prodigiosin and electron transport chain inhibitors

Axenic cultures of $T$. cruzi epimastigotes were treated with different concentrations of rotenone, TTFA, KCN, antimycin A, or prodigiosin for $24 \mathrm{~h}$. Rotenone and KCN had no effect on T. cruzi viability, while TTFA and antimycin A decreased the viability by 60 and $50 \%$, respectively. Both parasite strains tested (SN-3 and AF1c7) had similar responses to mitochondrial inhibitors (Figure 1). The activity of prodigiosin showed higher trypanocidal activity than the other mitochondrial inhibitors assayed. SN-3 and AF-1 c7 parasites showed a

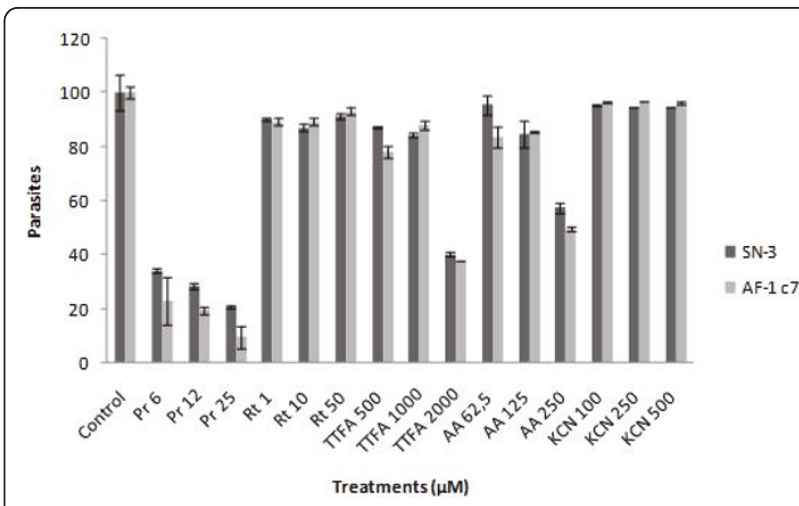

Figure 1 Activity of prodigiosin against Trypanosoma cruzi epimastigotes of the SN-3 strain and AF1 clone 7. $2 \times$

$10^{6}$ epimastigotes were treated with different concentrations of prodigiosin for $24 \mathrm{~h}$ and its viability was evaluated by flow

cytometry using propidium iodide.

small differential susceptibility to prodigiosin treatment. $\mathrm{SN}-3 \mathrm{IC}_{50}$ was $2.7 \mu \mathrm{M}$ while AF1 c7 $\mathrm{IC}_{50}$ was $2.2 \mu \mathrm{M}$ (p $<0.05$ ) (Figure 1). The $\mathrm{IC}_{50}$ to benznidazole was 34.62 and 4.69 to $\mathrm{SN}-3$ and $\mathrm{AF} 1 . \mathrm{SN}-3$ trypomastigotes treated with prodigiosin presented an $\mathrm{IC}_{50}$ of $3.2 \mu \mathrm{M}$, which is slightly higher than epimastigote $\mathrm{IC}_{50}$ (Figure 2). The $T$. cruzi AF-1 clone was unable to infect Vero cells. Thus, the prodigiosin effect on trypomastigote viability against this clone was not determined.

\section{Cytotoxicity assay}

To evaluate prodigiosin selectivity, Vero cells and human lymphocytes were treated with different concentrations of the compound for $24 \mathrm{~h}$. Indeed, as observed in Figure 3, prodigiosin had a slightly toxic effect on the viability of Vero cells, with $\mathrm{IC}_{50} 6.49 \pm$ 0.8 and a selectivity index $\left(\mathrm{IC}_{50}\right.$ Vero cells/ $\mathrm{IC}_{50}$ parasites) of 2.2 (SN3) and 2.49 (AF1 c7). However, on human lymphocytes, the toxic effects of prodigiosin

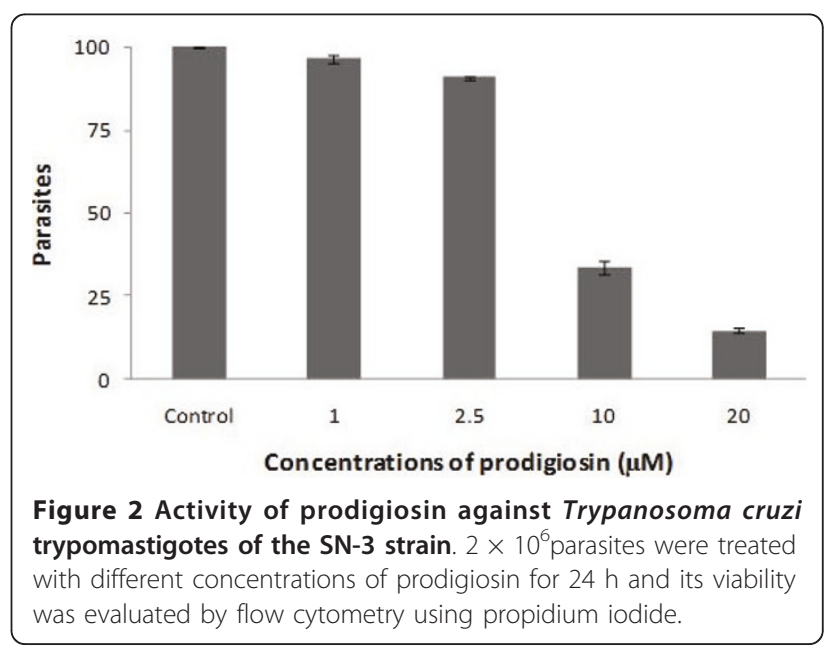



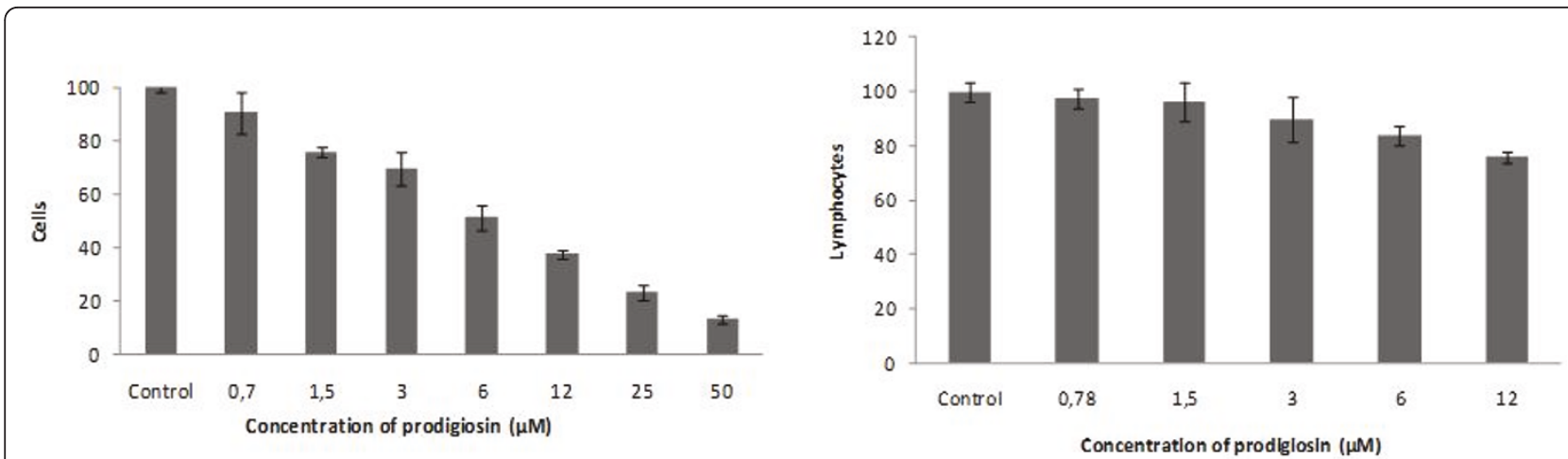

Figure 3 Activity of prodigiosin against Vero cells and human lymphocytes. $2.5 \times 10^{6}$ adherent Vero cells were treated with prodigiosin for $24 \mathrm{~h}$. After incubation, the supernatant and the adherent cells, previously dislodged, were used to quantify live cells by propidium iodide. $2 \times$ $10^{5}$ lymphocytes were treated with prodigiosin for $24 \mathrm{~h}$. The lives cells were counting by optical microscopy using the trypan blue dye.

were minimal with less of $25 \%$ cell death at 6 times the $\mathrm{IC}_{50}$ concentration (Figure 3 ).

\section{Mitochondrial function assays Effects on oxygen uptake}

To study the prodigiosin effects on oxygen uptake, we used the mitochondrial inhibitors TTFA and KCN as controls. Table 1 shows the effects of TTFA, KCN, and prodigiosin on oxygen uptake. $\mathrm{KCN}$ inhibited mitochondrial respiration by $50 \%$, while prodigiosin and TTFA inhibited parasite respiration by more than $80 \%$. These results indicate that the mitochondrial function is altered and that oxidative phosphorylation does not take a normal course. On the other hand, the addition of duroquinol, but not succinate, to prodigiosin-treated epimastigotes re-established and increased oxygen uptake, indicating that inhibition of respiration in $T$. cruzi could occur mainly due to the blockade of complex III (Figure 4). No effect of DMSO alone, in which prodigiosin was dissolved, was observed.

\section{Mitochondrial transmembrane potential ( $\Psi \mathrm{m})$ measurements}

We studied the $\Psi \mathrm{m}$ through incorporation of the TMRM probe, to determine whether the effects of prodigiosin on
T. cruzi mitochondria were associated with the metabolic function of this organelle. We characterized the T. cruzi $\Psi \mathrm{m}$ using the classic mitochondrial inhibitors rotenone, TTFA, KCN, and antimycin A. Subsequently, parasites were incubated with TMRM after $1 \mathrm{~h}$ of treatment with prodigiosin or mitochondrial inhibitors, and TMRM fluorescence was measured by flow cytometry after 30 min of incubation. The uncoupler CCCP was used as positive control. Our results show that both rotenone and $\mathrm{KCN}$ have little effect on $\Psi \mathrm{m}$, while TTFA and antimycin A decrease the $\Psi \mathrm{m}$ after $1 \mathrm{~h}$ of treatment (Figure $5)$. Conversely, prodigiosin demonstrated a dose-dependent membrane hyperpolarization. This hyperpolarization was similar in both the T. cruzi SN-3 strain and AF1 c 7 (data not shown), indicating that the mechanism of action in both parasite strains is similar.

\section{Discussion}

Herein we report the activity of prodigiosin against $T$. cruzi, and provide evidence that its mode of action involves the mitochondrial function. Current therapy for Chagas disease is not $100 \%$ effective. This picture is complicated by the fact that nifurtimox and benznidazole produce a wide variety of adverse events that may necessitate suspension of treatment. In addition, several

Table 1 Effect of prodigiosin, TTFA, and KCN on mitochondrial respiration.

\begin{tabular}{|c|c|c|c|c|}
\hline & Oxygen uptake & $\begin{array}{l}\text { Oxygen uptake after } \\
\text { succinate }\end{array}$ & $\begin{array}{l}\text { Oxygen uptake after } \\
\text { duroquinol }\end{array}$ & $\begin{array}{l}\text { Oxygen uptake after TMPD/ } \\
\text { ascorbate }\end{array}$ \\
\hline & $\mathrm{nmol} \mathrm{O}_{2} / \mathrm{min} / \mathrm{mg}$ protein & $\mathrm{nmol} \mathrm{O}_{2} / \mathrm{min} / \mathrm{mg}$ protein & $\mathrm{nmol} \mathrm{O}_{2} / \mathrm{min} / \mathrm{mg}$ protein & $\mathrm{nmol} \mathrm{O}_{2} / \mathrm{min} / \mathrm{mg}$ protein \\
\hline Control & 13.88889 & - & - & - \\
\hline Prodigiosin (5 mM) & 2.46667 & 2.46667 & 6.53333 & 44.66667 \\
\hline TTFA (5 mM) & 2.23333 & ND & ND & ND \\
\hline KCN (5 mM) & 6.76722 & ND & ND & ND \\
\hline
\end{tabular}

Oxygen consumption was evaluated in control and treated parasites. In order to determine which complexes of the electron transport chain were involved in the abnormal respiration, we added electron donors for each one of the complexes. The untreated parasites showed a higher oxygen uptake with respect to prodigiosin TTFA- and KCN-treated parasites. However, when electron donors for complex II and III were added the oxygen uptake was increased. 


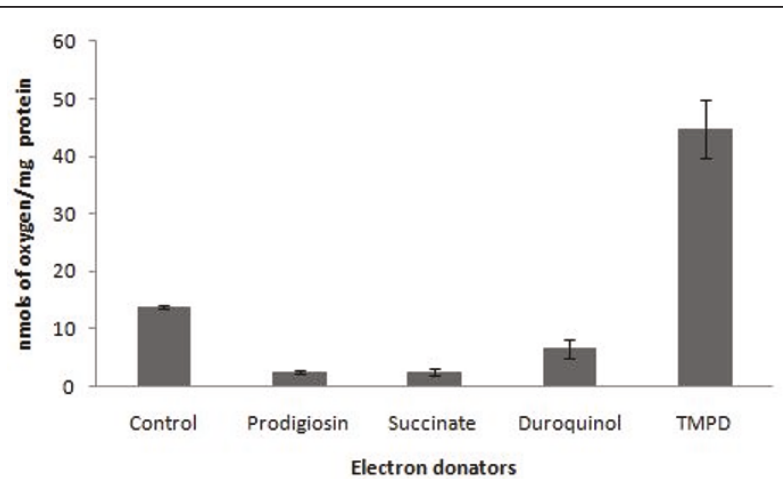

Figure 4 Effects of prodigiosin on mitochondrial electron transport chain. Electron donators were added after the addition of prodigiosin $(0.287 \mu \mathrm{M}$ to $5 \mathrm{mM})$ to the oxygen consumption reaction mix, and oxygen uptake was determined.

strains have been identified that are resistant to these drugs [1].

Diverse approaches have been used to search for new trypanocidal compounds, from natural and synthetic sources. Here, we propose a potentially useful trypanocidal agent that is derived from knowledge of an important aspect of the natural life cycle of the parasite: the vector-parasite interaction. Indeed, basic biological factors such as the food supply, intestinal components, gut flora, and insect physiology, which are relevant to understanding the parasite-vector interaction reveal new perspectives for the control of Chagas disease. Although Trypanosoma cruzi and triatomines probably did not co-evolve to facilitate protozoan transmission [16], it is clear that Chagas disease is dependent on a high degree of interaction between the triatomine vectors and the parasites.

The co-evolution of parasites and insects necessarily promoted the development of strategies based on both insect vector and parasite mechanisms, maintaining an

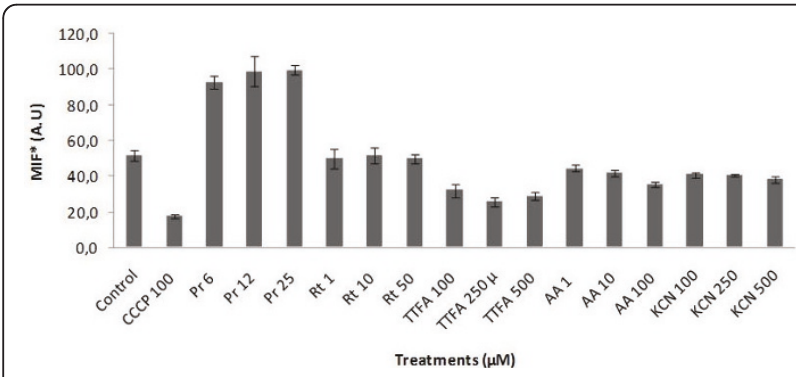

Figure 5 Effect of prodigiosin on mitochondrial transmembrane potential of epimastigotes of $T$. cruzi SN-3 strain. $1.5 \times 10^{6}$ parasites $/ \mathrm{mL}$ were treated with rotenone, TTFA, antimycin $\mathrm{A}, \mathrm{KCN}$, or prodigiosin for $1 \mathrm{~h}$. The parasites were then incubated with TMRM and analyzed with a cytometer. The uncoupler CCCP $(100 \mu \mathrm{M})$ was used as positive control. *MIF: Medium intensity of fluorescence. ecological equilibrium that might facilitate parasite development in the invertebrate host. Multiple factors are present in the insect vector gut that explain the establishment of T. cruzi colonization. One outstanding factor is the potential influence of the gut microbiota on the parasite life cycle. In this respect, following a blood meal, bacterial populations in the triatomines' midgut often undergo massive rapid expansions, as much as 10,000-fold [7]. Many microbial factors may be produced in the vector gut to target parasites ingested with a blood meal. These include pigments such as prodigiosin that are produced by the Gram-negative bacteria $S$. marcescens, S. plymuthica, and Streptomyces [17], all of which occur in the midgut of vector insects. Prodigiosin induces apoptotic phenomena and cell death in cancer cell lines [18]. In addition, it has been reported to have a strong inhibitory effect on a V79 fibroblast cell line [19]. However, other studies failed to demonstrate cytotoxicity against normal cells as compared with tumor cells lines [20]. In addition, prodigiosin derivatives show marked activity against Plasmodium falciparum [21], and strong activity against $T$. cruzi has also been reported [19].

To study the mode of action of prodigiosin on $T$. cruzi, we focused our research on the mitochondrial function. T. cruzi has only one mitochondrium, which is fundamental to parasite survival and regulation of the processes related to energy balance and apoptosis modulation. We focused on two points in mitochondrial metabolism. The first was oxygen consumption, a key step in oxidative phosphorylation inside the mitochondrial matrix, and the second was the mitochondrial membrane potential $(\boldsymbol{\Psi} \mathbf{m})$. $\Psi \mathrm{m}$ is crucial for ATP production by ATP synthase, and it is also involved in protein transport inside the organelle and in regulation of the glycolysis process. Moreover, its variations are used as an earlier marker of mammalian and protozoan programmed cell death (PCD) progression.

In order to validate our experimental strategy, we studied the effects of classic mitochondrial inhibitors. The results showed that rotenone and $\mathrm{KCN}$, electron transport chain inhibitors of complex I and IV, respectively, do not have an effect on T. cruzi viability, and caused slight or no $\Psi \mathrm{m}$ and cellular respiration alterations. Our data confirm the results obtained by other groups suggesting that $T$. cruzi complex I is absent or at least cannot be inhibited by rotenone [22] and complex IV might have an alternative pathway, probably mediated by a trypanosome alternative oxidase as described for T. bruce $i$ $[23,24]$. The existence of mitochondrial complex I in trypanosomatids is still a matter of intense discussion. Recently, a very detailed bioinformatic analysis to predict the composition of a putative trypanosomatid complex I revealed the presence of all subunits known to be 
involved in complex I-electron transport, but four membrane subunits assumed to be involved in proton extrusion are missing, suggesting that this complex is not involved in energy transduction [25]. In this sense, experimental data obtained in T. cruzi natural strains containing deletions in the ND4, ND5 and ND7 genes coding for complex I subunits demonstrated that this complex is not functional in NADH oxidation and also is not involved in energy transduction [26]. Furthermore, a RNAi study against the putative subunits of complex I of T. brucei revealed the presence of this complex and its participation in electron transport, although this complex does not play an important role in energy metabolism of the T. brucei procyclics [27]. Taking together, these results and those reported in this study, indicate that the function of mitochondrial complex I remain a very intriguing issue to be studied.

On the other hand, the treatment with TTFA, a succinate dehydrogenase (complex II) inhibitor, was able to induce considerable dysfunction of the T. cruzi mitochondria, which was evidenced by a decrease in membrane depolarization, respiration and cell viability. It has been suggested that the complex II in T. cruzi is the main electron sink from the Krebs cycle and its importance in energy transduction is clear [22]. Similarly, the treatment with the complex III inhibitor antimycin A showed a similar effect to the TTFA, inducing a loss of mitochondrial intermembrane potential and decreasing respiration and cell viability. All of these results are in concordance with previous reports showing the importance of complex II and III in the maintenance of mitochondrial stability in T. cruzi.

On the other hand, potassium cyanide was able to induce the blockage of cellular respiration in at least $50 \%$ of oxygen uptake. Similar results have been reported in other mitochondrial respiration studies $[28,29]$. KCN treatment did not induce a decrease on the $\Psi \mathrm{m}$ or even on parasite viability. It has been suggested that $T$. cruzi have three respiratory terminals: 1 ) A respiratory terminal sensitive to cyanide and azide; 2 ) a cyanide-sensitive but azide-insensitive terminal; and 3) a terminal insensitive to both inhibitors.

Taking all the results obtained with the mitochondrial electron transport chain inhibitors, we concluded that the behavior and measurements made show the methodology's confidence in studying other different stimuli such as prodigiosin.

The mitochondrial alterations observed during prodigiosin treatment included an important inhibition of oxygen consumption, probably due to the action of prodigiosin throughout the electron transport chain. The use of electron donators allowed us to propose that one of the effects of prodigiosin inside T. cruzi mitochondria could be associated to complex III blockage, although complex II also presented a slight reactivation after succinate addition. To confirm our hypothesis we studied the $\Psi \mathrm{m}$ behavior. The $\Psi \mathrm{m}$ is one of the most important events inside the mitochondria of several cell types and usually a decrease of $\Psi \mathrm{m}$ is associated with PCD [30]. Furthermore, hyperpolarization has been identified as an early event related with $\mathrm{H}_{2} \mathrm{O}_{2}$ [31], p53 [32], and staurosporin-induced apoptosis [33]. Due to $\Psi \mathrm{m}$ hyperpolarization and extrusion of $\mathrm{H}^{+}$ions from the mitochondrial matrix, the cytochromes within the electron transport chain become more reduced, which favors the generation of reactive oxygen intermediates (ROI). Thus, mitochondrial hyperpolarization is a likely cause of ROI production at early stages, representing a key checkpoint in cell-fate decision [34,35]. Indeed, prodigiosin induced a marked hyperpolarization of the mitochondria after 1 $\mathrm{h}$ of treatment, suggesting that prodigiosin could act on an early stage of an apoptotic-like cell death pathway. All these results indicate that processes related to the functional and structural stability of mitochondria in $T$. cruzi are altered and could govern the success of programmed cell death pathways in prodigiosin-treated $T$. cruzi parasites.

These findings are consistent with several reports where the mode of action of prodigiosin is related to mitochondrial alterations. The main effects include modifications of oxygen uptake, ATP production, and $\Psi \mathrm{m}$ that conduce to cell death by an apoptotic process [13]. Recently, an apoptotic cell death process was discovered in protozoan parasites such as T. brucei, Leishmania sp, and T. cruzi [36-38]. In these organisms, the pathways associated to apoptosis progression remain to be elucidated, and the mitochondrial role is unclear; however, some recent works suggest that disturbances of this organelle can induce a similar mammalian apoptotic phenotype [39-45].

Thus, we propose that the anti-T. cruzi prodigiosin effect could be facilitated through an apoptotic-like phenomenon mediated by induction of mitochondrial dysfunction, analogous to that reported for cancer cells [13-15]. It is possible to speculate that the apoptotic progression of epimastigotes inside the insect gut might result in at least three different populations of virulent feces (epimastigotes, trypomastigotes, and dead parasites). If the parasitic apoptotic population from the vector is capable of interacting with immune cells of the vertebrate host, it is likely that the resulting attenuation of the immune response might contribute to $T$. cruzi evasion of the host immune response [46]. This would thus facilitate Chagas disease progression [47], as previously demonstrated and suggested in Leishmania infantum by Zandbergen et al. $[48,49]$.

Finally, our results indicate that prodigiosin could be a good candidate for the treatment of Chagas disease, 
because we compared the activity of prodigiosin and benznidazole, demonstrating a lower $\mathrm{IC}_{50}$. Future research is needed to clarify these findings and the role of prodigiosin in mitochondrial complex III.

\section{Conclusions}

Our results indicate that prodigiosin could be a good candidate for the treatment of Chagas disease. We compared the activity of prodigiosin in two different lineages of $T$. cruzi and both showed a low $\mathrm{IC}_{50}$, which is lower than that of benznidazole. However, further research is needed to address these issues and to confirm the advantages of mitochondrial intermembrane potential measurements as a crucial and useful indicator of the biochemical status of kinetoplastid parasites.

\section{Methods}

\section{Parasites}

Trypanosoma cruzi epimastigotes of the SN-3 strain (TC I) and AF-1 clone 7 (TC II), both obtained from triatomines, were cultured at $28^{\circ} \mathrm{C}$ in LIT medium supplemented with $10 \%$ FBS. Trypomastigote forms were obtained from SN-3 strain-infected Vero cells and collected from the culture media by centrifugation at $500 \mathrm{~g}$ for $3 \mathrm{~min}$. The supernatant was discarded and fresh RPMI medium was added to the resultant pellet. Tubes were incubated for $2 \mathrm{~h}$ to allow the trypomastigotes to swim out of the pellet. The resulting suspension was then centrifuged and the pellet was suspended in fetal bovine serum-RPMI culture medium at a final density of $2 \times 10^{7}$ trypomastigotes $/ \mathrm{mL}$.

\section{Bacterial strain}

Wild-type Serratia marcescens that produces prodigiosin was donated from the School of Medicine, University of Antioquia. S. marcescens was characterized using the biochemical test API-20. The bacterial cultures were maintained in nutritive agar for $24 \mathrm{~h}$ at $30^{\circ} \mathrm{C}$.

\section{Reagents and inhibitors}

The electron transport chain inhibitors Rotenone (specific complex I inhibitor), 2-thenoyltrifluoroactone -TTFA- (specific complex II inhibitor), antimycin A (specific complex III inhibitor), potassium cyanide -KCN- (specific complex IV inhibitor), the uncoupler carbonyl cyanide 3-cholophenylhydrazone (CCCP), and all other reagents used were from Sigma-Aldrich.

\section{Prodigiosin isolation}

Prodigiosin was extracted by $S$. marcescens lysis with a mixture of methanol/1N HCl (24:1). After centrifugation at $2000 \mathrm{~g}$ for $10 \mathrm{~min}$, the solvent in supernatant was removed using a rotary evaporator system. Atmospheric pressure liquid chromatography of the extract was performed on a silica gel with dichloromethane and methanol as solvents. The eluted pigmented fractions were pooled and the dichloromethane/methanol extract was vacuum evaporated, redissolved in methanol, and characterized by H-NMR.

\section{Prodigiosin and inhibitors activity}

Epimastigotes and trypomastigotes at a density of $2 \times$ $10^{6}$ per $\mathrm{mL}$ were treated with different concentrations of mitochondrial electron transport chain inhibitors or prodigiosin for $24 \mathrm{~h}$. Moreover, epimastigotes were exposed to benznidazole with the aim of identifying the $\mathrm{IC}_{50}$. Culture growth was followed by flow cytometry with propidium iodide as a viability marker. $\mathrm{IC}_{50}$ values were calculated by linear regression analysis of the relation between drug concentration and cell viability.

\section{Cytotoxicity assay}

The effect of prodigiosin on Vero cells and human lymphocytes was evaluated through flow cytometry and microscopy counting, respectively. First, $2.5 \times 10^{6}$ cells were incubated in RPMI 1640, 2\% FCS supplemented medium for $24 \mathrm{~h}$ at $37^{\circ} \mathrm{C}$ with $5 \% \mathrm{CO}_{2}$ to secure their adherence. Cells were then treated with prodigiosin concentrations ranging from $0.625 \mu \mathrm{M}$ to $50 \mu \mathrm{M}$ for $24 \mathrm{~h}$. After treatment, the supernatant and the dislodged adherent cells were used to quantify the live cells by propidium iodide staining. Cells treated with PBS or DMSO 30\% were used as negative and positive controls, respectively. The cytotoxic assays for human lymphocytes were carried out using isolated lymphocytes by Ficoll-Paque gradient from a volunteer [50]. A total of 2 $\times 10^{5}$ cells were cultivated in RPMI $1640,10 \%$ FCS supplemented medium for $48 \mathrm{~h}$ at $37^{\circ} \mathrm{C}$ with $5 \% \mathrm{CO}_{2}$. Lymphocytes were treated with prodigiosin concentrations ranging from $0.78 \mu \mathrm{M}$ to $12 \mu \mathrm{M}$ for $24 \mathrm{~h}$. After treatment, the lymphocytes were used to quantify the live cells by trypan blue staining. Lymphocytes treated with PBS or $\mathrm{H}_{2} \mathrm{O}_{2} 50 \mu \mathrm{M}$ were used as negative and positive controls, respectively.

\section{Mitochondrial function assays Oxygen uptake assay}

T. cruzi epimastigotes were harvested by $500 \times g$ centrifugation, washed twice, and suspended in $0.05 \mathrm{M}$ sodium phosphate and $0.107 \mathrm{M}$ sodium chloride buffer, $\mathrm{pH}$ 7.4. Respiration measurements were carried out polarographically with a Clark no. 5331 electrode (Yellow Springs Instruments) in a 53 YSI model (Simpson Electric Co) [51]. The chamber volume was $0.6 \mathrm{~mL}$ and the temperature was $28^{\circ} \mathrm{C}$. The amount of parasite used was equivalent to $1 \mathrm{mg} / \mathrm{mL}$ of protein. To study the performance of cellular respiration we used several concentrations of TTFA, $\mathrm{KCN}$, or prodigiosin as treatments. In 
addition, to study the effect of prodigiosin on succinate dehydrogenase (complex II), cytochrome c reductase (complex III) and cytochrome c oxidase (complex IV), we added succinate $5 \mathrm{mM}$, duroquinol $0.5 \mathrm{mM}$, and TMPD $0.1 \mathrm{mM} /$ ascorbate $10 \mathrm{mM}$, respectively, after having added prodigiosin at concentrations from 0.287 $\mu \mathrm{M}$ to $5 \mathrm{mM}$. Oxygen uptake was then determined. Values are expressed as mean \pm SD for three independent experiments.

\section{Mitochondrial transmembrane potential ( $\Psi \mathrm{m})$}

Parasites in LIT medium/10\% FCS at $1.5 \times 10^{6}$ parasites $/ \mathrm{mL}$ were treated with rotenone, TTFA, antimycin $\mathrm{A}, \mathrm{KCN}$, or prodigiosin for $1 \mathrm{~h}$. The treated parasites were then incubated with $1 \mathrm{uM}$ tetramethylrhodamine methyl ester perchlorate (TMRM, Sigma CAT\# T5428) and analyzed with a cytometer. TMRM loading was carried out at $28^{\circ} \mathrm{C}$ in all treated and control parasites. The uncoupler CCCP (100 uM) was used as a positive control.

\section{Acknowledgements and Funding}

The authors express their acknowledgement of the Department of Microbiology of the School of Medicine of the University of Antioquia for the Serratia marcescens strain. Juan Fernando Alzate is thanked for fruitful discussions and advices on some experiments. Grant support came from the Cooperacion Internacional Conicyt-Colciencias 2007-152 and the Conicyt Associative Research Programme ACT112 grant. In Colombia this research was supported by proyecto sostenibilidad BCEI 2010, CODI, UdeA.

\section{Author details}

'Grupo Biología y Control de Enfermedades Infecciosas BCEI - SIU, Instituto de Biología, Universidad de Antioquia, Medellín, Colombia. ${ }^{2}$ Grupo de Química de Productos Naturales - SIU, Instituto de Biología, Universidad de Antioquia, Medellín, Colombia. ${ }^{3}$ Programa de Farmacología Molecular y Clínica. ICBM. Facultad de Medicina. Universidad de Chile, Santiago, Chile.

\section{Authors' contributions}

CG, JM and OT designed the study and drafted the manuscript. CG did the laboratory work and analyzed the data. EB and FE designed and supervised the prodigiosin purification procedures and critically revised the manuscript All authors read and approved the final manuscript.

\section{Competing interests}

The authors declare that they have no competing interests.

Received: 10 February 2011 Accepted: 6 May 2011

Published: 6 May 2011

\section{References}

1. Chagas Disease report. World Health Organization;[http://www.who.int/ mediacentre/factsheets/fs340/en/

2. Clayton J: Chagas disease: pushing through the pipeline. Nature 2010, 465(7301):S12-15.

3. Maya JD, Cassels B, Galanti N, Morello A: Mode of action of natural and synthetic drugs against Trypanosoma cruzi and their interaction with the mammalian host. Comp Biochem Physiol A Mol Integr Physiol 2007, 146(4):601-620.

4. Castro DP, Seabra SH, Garcia ES, de Souza W, Azambuja P: Trypanosoma cruzi: ultrastructural studies of adhesion, lysis and biofilm formation by Serratia marcescens. Exp Parasitol 2007, 117(2):201-207.

5. Azambuja P, Garcia ES, Ratcliffe NA: Gut microbiota and parasite transmission by insect vectors. Trends Parasitol 2005, 12:568-572.
6. Durvasula RV, Sundaram RK, Kirsch P, Hurwitz I, Crawford CV, Dotson E, Beard CB: Genetic transformation of a Corynebacterial symbiont from the Chagas disease vector Triatoma infestans. Exp Parasitol 2008, 119(1):94-98.

7. Azambuja P, Feder D, Garcia ES: Isolation of Serratia marcescens in the midgut of Rhodnius prolixus: impact on the establishment of the parasite Trypanosoma cruzi in the vector. Exp Parasitol 2004, 107(1-2):89-96.

8. Williamson NR, Fineran PC, Gristwood T, Chawrai SR, Leeper FJ, Salmond GP: Anticancer and immunosuppressive properties of bacterial prodiginines. Future Microbiol 2007, 2:605-618.

9. Pérez-Tomás R, Viñas M: New insights on the antitumoral properties of prodiginines. Curr Med Chem 2010, 17(21):2222-2231.

10. Pérez-Tomás R, Montaner B, Llagostera E, Soto-Cerrato V: The prodigiosins, proapoptotic drugs with anticancer properties. Biochem Pharmacol 2003, 66(8):1447-1452.

11. Paik PK, Rudin CM, Brown A, Rizvi NA, Takebe N, Travis W, James L, Ginsberg MS, Juergens R, Markus S, Tyson L, Subzwari S, Kris MG, Krug LM: A phase I study of obatoclax mesylate, a $\mathrm{Bcl}-2$ antagonist, plus topotecan in solid tumor malignancies. Cancer Chemother Pharmacol 2010, 66(6):1079-1085.

12. Konno H, Matsuya H, Okamoto M, Sato T, Tanaka Y, Yokoyama K, Kataoka T, Nagai K, Wasserman HH, Ohkuma S: Prodigiosins uncouple mitochondrial and bacterial F-ATPases: evidence for their $\mathrm{H}+/ \mathrm{Cl}$ - symport activity. J Biochem 1998, 124(3):547-556.

13. Soto-Cerrato V, Llagostera E, Montaner B, Scheffer GL, Perez-Tomas R: Mitochondria-mediated apoptosis operating irrespective of multidrug resistance in breast cancer cells by the anticancer agent prodigiosin. Biochem Pharmacol 2004, 68(7):1345-1352.

14. Llagostera E, Soto-Cerrato V, Montaner B, Pérez-Tomás R: Prodigiosin induces apoptosis by acting on mitochondria in human lung cancer cells. Ann N Y Acad Sci 2003, 10:178-181.

15. Francisco R, Pérez-Tomás R, Giménez-Bonafé $P$, Soto-Cerrato $V$, GiménezXavier $\mathrm{P}$, Ambrosio S: Mechanisms of prodigiosin cytotoxicity in human neuroblastoma cell lines. Eur J Pharmacol 2007, 572(2-3):111-119.

16. Takano-Lee M, Edman JD: Lack of manipulation of Rhodnius prolixus (Hemiptera: Reduviidae) vector competence by Trypanosoma cruzi. J Med Entomol 2002, 39(1):44-51.

17. Williamson NR, Fineran PC, Leeper FJ, Salmond GP: The biosynthesis and regulation of bacterial prodiginines. Nat Rev Microbiol 2006, 4(12):887-899.

18. Montaner B, Pérez-Tomás R: The prodigiosins: a new family of anticancer drugs. Curr Cancer Drug Targets 2003, 3(1):57-65.

19. Da Silva Melo P, Durán N, Haun M: Cytotoxicity of prodigiosin and benznidazole on V79 cells. Toxicol Lett 2000, 116(3):237-42

20. Zhou Wei, Zhi-Xiong Jin, Yong-Ji Wan: Apoptosis of human lung adenocarcinoma A549 cells induced by prodigiosin analogue obtained from an entomopathogenic bacterium Serratia marcescens. Appl Microbiol Biotechnol 2010, 88:1269-1275.

21. Isaka M, Jaturapat A, Kramyu J, Tanticharoen M, Thebtaranonth Y: Potent in vitro antimalarial activity of metacycloprodigiosin isolated from Streptomyces spectabilis BCC 4785. Antimicrob Agents Chemother 2002, 46(4):1112-1113.

22. Denicola-Seoane A, Rubbo H, Prodanov E, Turrens J: Succinate-dependent metabolism in Trypanosoma cruzi epimastigotes. Mol and Biochem Parasitol 1992, 54:43-50.

23. Van Hellemond JJ, Opperdoes FR, Tielens AGM: The extraordinary mitochondrion and unusual citric acid cycle in Trypanosoma brucei. Biochem Soc Trans 2005, 33(5):967-971.

24. Chaudhuri M, Ott RD, Hill GC: Trypanosome alternative oxidase: from molecule to function. Trends Parasitol 2006, 22(10):484-491.

25. Opperdoes FR, Michels PA: Complex I of Trypanosomatidae: does it exist? Trends Parasitol 2008, 24(7):310-317.

26. Carranza JC, Kowaltowski AJ, Mendonça MA, de Oliveira TC, Gadelha FR, Zingales B: Mitochondrial bioenergetics and redox state are unaltered in Trypanosoma cruzi isolates with compromised mitochondrial complex I subunit genes. J Bioenerg Biomembr 2009, 41(3):299-308.

27. Verner Z, Cermáková P, Skodová I, Kriegová E, Horváth A, Lukes J: Complex I (NADH:ubiquinone oxidoreductase) is active in but non-essential for procyclic Trypanosoma brucei. Mol Biochem Parasitol 2011, 175(2):196-200.

28. Stoppani AO, Docampo R, de Boiso JF, Frasch AC: Effect of inhibitors of electron transport and oxidative phosphorylation on Trypanosoma cruzi respiration and growth. Mol Biochem Parasitol 1980, 2(1):3-21. 
29. Carneiro M, Caldas RA: Evidence for three respiratory terminals in Trypanosoma cruzi epimastigotes. Acta Trop 1982, 39(1):41-49.

30. Armstrong JS: Mitochondrial membrane permeabilization: the sine qua non for cell death. BioEssays 2006, 28:253-260.

31. Puskas F, Gergely P Jr, Banki K, Perl A: Stimulation of the pentose phosphate pathway and glutathione levels by dehydroascorbate, the oxidized form of vitamin C. FASEB J 2000, 14(10):1352-1361.

32. Li PF, Dietz $R$, von Harsdorf $R$ : $p 53$ regulates mitochondrial membrane potential through reactive oxygen species and induces cytochrome c-independent apoptosis blocked by Bcl-2. EMBO J 1999, 1(21):6027-6036, 18

33. Scarlett JL, Sheard PW, Hughes G, Ledgerwood EC, Ku HH, Murphy MP: Changes in mitochondrial membrane potential during staurosporineinduced apoptosis in Jurkat cells. N.FEBS Lett 2000, 475(3):267-72.

34. Gergely P Jr, Niland B, Gonchoroff N, Pullmann R Jr, Phillips PE, Perl A: Persistent mitochondrial hyperpolarization, increased reactive oxygen intermediate production, and cytoplasmic alkalinization characterize altered IL-10 signaling in patients with systemic lupus erythematosus. J Immunol 2002, 169(2):1092-1101.

35. Nagy G, Koncz A, Perl A: T Cell Activation-Induced mitocondrial hyperpolarization is mediated by $\mathrm{Ca}^{2+}$ - and redox-dependent production of nitric oxide. J Immunol 2003, 171(10):5188-5197.

36. Ameisen JC: On the origin, evolution, and nature of programmed cell death: a timeline of four billion years. Cell Death Differ 2002, 9(4):367-393.

37. Ameisen JC, Idziorek T, Billaut-Mulot O, Loyens M, Tissier JP, Potentier A Ouaissi A: Apoptosis in a unicellular eukaryote (Trypanosoma cruzi): implications for the evolutionary origin and role of programmed cell death in the control of cell proliferation, differentiation and survival. Cell Death Differ 1995, 2(4):285-300.

38. Arnoult D, Akarid K, Grodert A, Ameisen J: On the evolution of programmed cell death: apoptosis of the unicellular eukaryote Leishmania major involves cysteine proteinase activation and mitochondrion permeabilization. Cell Death Differ 2002, 9(1):65-81.

39. Kosec G, Alvarez V, Aguero F: Metacaspases of Trypanosoma cruzi: Posible candidates for programmed cell death mediators. Mol Biochem Parasitol 2006, 145(1):18-28

40. Rico E, Alzate JF, Arias AA, Moreno D, Clos J, Gago F, Moreno I, Domínquez M, Jiménez-Ruiz A: Leishmania infantum expresses a mitochondrial nuclease homologous to EndoG that migrates to the nucleus in response to an apoptotic stimulus. Mol Biochem Parasitol 2009, 163(1):28-38.

41. Alzate J, Alvarez-Barrientos, Gonzales VM, Jimenes-Ruiz: Heat-induced programmed cell death in Leishmania infantum is reverted by $\mathrm{BCl}_{-\times \mathrm{l}}$ expression. Apoptosis 2006, 11(2):161-171.

42. Alzate JF, Arias A, Mollinedo F, Rico E, de la Iglesia-Vicente J, JiménezRuiz A: Edelfosine induces an apoptotic process in Leishmania infantum that is regulated by the ectopic expression of Bcl-XL and Hrk. Antimicrob Agents Chemother 2008, 52(10):3779-3782.

43. Kaczanowski S, Sajid M, Reece S: Evolution of apoptosis-like programmed cell death in unicellular protozoan parasites. Parasit Vectors 2011, 4:44.

44. Smirlis D, Duszenko M, Jimenez-Ruiz A, Scoulica E, Bastien P, Fasel N, Soteriodou K: Targeting essential pathways in trypanosomatids give insights into protozoan mechanism of cell death. Parasit Vectors 2010, 3:107

45. Jimenez-Ruíz A, Alzate JF, Macleod ET, Lüder CG, Fasel N, Hurd H: Apoptotic markers in protozoan parasites. Parasit Vectors 2010, 3:104.

46. Freire-de-Lima CG, Nascimento DO, Soares MB, Bozza PT, Castro-FariaNeto HC, de Mello FG, DosReis GA, Lopes MF: Uptake of apoptotic cells drives the growth of a pathogenic trypanosome in macrophages. Nature 2000, 403(6766):199-203.

47. Dos Reis GA, Lopes M: The importance of apoptosis for immune regulation in Chagas disease. Mem Inst Oswaldo Cruz 2009, 104(1):259-262.

48. Van Zandbergen G, Bollinger A, Wenzel A, Kamhawi S, Voll R, Klinger $M$ Müller A, Hölscher C, Herrmann M, Sacks D, Solbach W, Laskay T: Leishmania disease development depends on the presence of apoptotic promastigotes in the virulent inoculum. Proc Natl Acad Sci USA 2006, 103(37):13837-13842

49. Van Zandbergen, Lüder C, Heussler V, Duszenko M: Programmed cell death in unicellular parasites: a prerequisite for sustained infection? Trends Parasitol 2010, 10:477-483.
50. Pelegrí C, Rodríguez-Palmero M, Morante MP, Comas J, Castell M, Franch A: Comparison of four lymphocyte isolation methods applied to rodent $T$ cell subpopulations and B cells. J Immunol Methods 1995, 187(2):265-271.

51. Morello A, Pavani M, Garbarino JA, Chamy MC, Frey C, Mancilla J, Guerrero A, Repetto Y, Ferreira J: Effects and mode of action of 1,4naphthoquinones isolated from Calceolaria sessilis on tumoral cells and Trypanosoma parasites. Comp Biochem Physiol C Pharmacol Toxicol Endocrinol 1995, 112(2):119-128.

doi:10.1186/1756-3305-4-66

Cite this article as: Genes et al:: Mitochondrial dysfunction in

Trypanosoma cruzi: the role of Serratia marcescens prodigiosin in the alternative treatment of Chagas disease. Parasites \& Vectors 2011 4:66.

\section{Submit your next manuscript to BioMed Central and take full advantage of:}

- Convenient online submission

- Thorough peer review

- No space constraints or color figure charges

- Immediate publication on acceptance

- Inclusion in PubMed, CAS, Scopus and Google Scholar

- Research which is freely available for redistribution

Submit your manuscript at www.biomedcentral.com/submit
Ciomed Central 